\title{
Risk factors for coronary artery disease in nursing students
}

\author{
Fatores de risco para doença arterial coronariana em estudantes de enfermagem \\ Factores de riesgo de enfermedad coronaria en estudiantes de enfermería
}

Hadassa da Silva Caldeira de Moraes'
ORCID: 0000-0001-9812-835X
Paula Vanessa Peclat Flores'
ORCID: 0000-0002-9726-5229

Ana Carla Dantas Cavalcanti ORCID: 0000-0003-3531-4694

Lyvia da Silva Figueiredo' ORCID: 0000-0003-1591-422X

Juliana de Melo Vellozo Pereira Tinoco' ORCID: 0000-0002-2418-6984

'Universidade Federal Fluminense. Niterói, Rio de Janeiro, Brazil.

How to cite this article: Moraes HSC, Flores PVP, Cavalcanti ACD, Figueiredo LS Tinoco JMVP. Risk factors for coronary artery disease in nursing students. Rev Bras Enferm. 2021;74(1):e20190824. doi: http://dx.doi.org/10.1590/0034-7167-2019-0824

Corresponding author: Hadassa da Silva Caldeira de Moraes E-mail: hadassa.moraes@hotmail.com

EDITOR IN CHIEF: Dulce Barbosa ASSOCIATE EDITOR: Marcos Brandão

Submission: $03-10-2020$

Approval: 09-13-2020

\begin{abstract}
Objectives: to identify and discuss the main risk factors for coronary artery disease, observed in nursing students. Methods: an observational and cross-sectional study conducted with nursing students at a public college in Niterói, RJ. Data collection involved instruments validated for use in Brazil. PROCAM Quick Check score was used to estimate cardiovascular risk. Results: of the 110 students, $88(80 \%)$ were female, with a mean age of $22.03 \pm 3.63$ years. The most relevant cardiovascular risk factors were alcohol consumption $62(56.4 \%)$ family history of coronary artery disease $35(31.8 \%)$, poor eating habits $(49.5 \%)$ and stress, whose domain "Professional training" received the highest mean, with $11.62 \pm 3.42$ points. Conclusions: the most frequent risk factors in nursing students are stress, inadequate nutrition and risky consumption of alcoholic beverages. These present a low risk for coronary artery disease through PROCAM Quick Check score.
\end{abstract}

Descriptors: Coronary Artery Disease; Atherosclerosis; Cardiovascular Diseases; Students, Nursing; Risk Factors.

\section{RESUMO}

Objetivos: identificar e discutir os principais fatores de risco para doença arterial coronariana, observados nos estudantes de enfermagem. Métodos: estudo observacional transversal com estudantes de enfermagem de uma universidade pública em Niterói, RJ. A coleta de dados envolveu instrumentos validados para uso no Brasil. O escore PROCAM Quick Check foi utilizado para estimar o risco cardiovascular. Resultados: dos 110 estudantes, 88 (80\%) eram do sexo feminino, com média de idade de 22,03 $\pm 3,63$ anos. Os fatores de risco cardiovasculares mais relevantes foram consumo de bebida alcoólica $62(56,4 \%)$, história familiar de Doença Arterial Coronariana 35 (31,8\%), hábitos alimentares ruins (49,5\%) e estresse, cujo domínio "Formação Profissional" recebeu a maior média, com 11,62 $\pm 3,42$ pontos. Conclusões: os fatores de risco mais frequentes em estudantes de enfermagem são estresse, alimentação inadequada e consumo de risco de bebida alcoólica. Estes apresentam baixo risco para doença arterial coronariana através do escore PROCAM Quick Check.

Descritores: Doença da Artéria Coronariana; Aterosclerose; Doenças Cardiovasculares; Estudantes de Enfermagem; Fatores de Risco.

\section{RESUMEN}

Objetivos: identificar y discutir los principales factores de riesgo de enfermedad coronaria observados en estudiantes de enfermería. Métodos: estudio observacional, transversal con estudiantes de enfermería de una universidad pública de Niterói, RJ. La recolección de datos involucró instrumentos validados para su uso en Brasil. Se utilizó la puntuación PROCAM Quick Check para estimar el riesgo cardiovascular. Resultados: de los 110 estudiantes, $88(80 \%)$ eran mujeres, con una edad media de $22,03 \pm 3,63$ años. Los factores de riesgo cardiovascular más relevantes fueron el consumo de alcohol 62 (56,4\%), los antecedentes familiares de enfermedad coronaria 35 (31,8\%), los malos hábitos alimentarios $(49,5 \%)$ y el estrés, cuyo dominio "Entrenamiento profesional" recibió el promedio más alto, con $11,62 \pm 3,42$ puntos. Conclusiones: los factores de riesgo más frecuentes en los estudiantes de enfermería son el estrés, la nutrición inadecuada y el consumo de bebidas alcohólicas de riesgo. Estos presentan un riesgo bajo de enfermedad de las arterias coronarias a través de la puntuación PROCAM Quick Check.

Descriptores: Enfermedad de la Arteria Coronaria; Aterosclerosis; Enfermedades Cardiovasculares; Estudiantes de Enfermería; Factores de Riesgo. 


\section{INTRODUCTION}

Cardiovascular diseases are the leading causes of death in Brazil, and there is a progressive increase in the number of cases, and risk factors that contribute coronary artery disease (CAD) development have grown in epidemic proportions in recent years. Data from the Ministry of Health $(\mathrm{MoH})$ indicate that, in Brazil, between January 2017 and 2018, there were approximately $1,209,513$ million hospitalizations and 99,478 deaths due to circulatory system diseases. Among the Brazilian regions, southeastern Brazil presented 47,224 deaths, and northeastern Brazil, 24,506 deaths, occupying, respectively, the first and second place in this ranking ${ }^{(1)}$.

Risk factors, such as dyslipidemia, smoking, high blood pressure, insulin resistance, physical inactivity and obesity are directly related to the development of cardiovascular diseases. For decades, such factors were considered relevant only in individuals with advanced age $\mathrm{e}^{(2)}$. Although cardiovascular disease (CVD) has a prolonged latency period, such risk factors start early ${ }^{(3)}$.

Recent studies, such as ERICA (Estudo de Riscos Cardiovasculares em Adolescentes), have shown that the appearance of CVD has manifested itself more and more early, with a higher prevalence of obesity and chronic diseases being detected among younger people ${ }^{(4)}$.

Among CVDs, CAD represents one of the greatest causes of morbidity and mortality worldwide, being the main cause of death in adult individuals in developed countries ${ }^{(5)}$. CAD manifestation has occurred more and more frequently among young people. Alarming data from the $\mathrm{MoH}$ indicate that, in January 2018 alone, $4,659,570.29$ million Brazilians manifested morbidity due to CAD and, of that total, 91,337.77 thousand are under 40 years old ${ }^{(1)}$.

CAD is a chronic inflammatory disease of multifactorial origin that occurs in response to endothelial aggression, affecting mainly the intima layer of medium and large caliber arteries. As a rule, preliminary lesions of the atherosclerotic plaque (fatty streaks), which correspond to the accumulation of cholesterol in macrophages, begin in childhood(6).

As a consequence, CAD can have significant socioeconomic impacts. From the control of its risk factors, the results can be favorable to interrupt follow-up in the population. Therefore, education, prevention and health promotion measures are crucial elements to prevent the first cardiovascular event, as it can be fatal, disabling, representing a high medical and social $\operatorname{cost}^{(5)}$. Most cardiovascular risk factors are modifiable and, if controlled, can contribute to reducing mortality ${ }^{(7)}$.

Students are an audience whose lifestyle and situations typical of academy can result in omission of meals, excessive consumption of snacks and nutritionally inadequate. High rates of physical inactivity and excess weight are detected in this group, in addition to high consumption of alcoholic beverages, smoking and stress, influencing their quality of life, predisposing their cardiovascular health to greater risk ${ }^{(2)}$.

An analysis of the prevalence that verified the simultaneity of four behavioral risk factors (physical inactivity, high fat consumption, alcohol abuse, and smoking) for CVD, in undergraduate students at a public college in Brazil, observed rates of $44.2 \%$ of alcohol abuse, $38.2 \%$ of physical inactivity, $21.9 \%$ of hypercholesterolemia and $14.6 \%$ of smoking; $24.2 \%$ had, at the same time, at least two risk factors ${ }^{(8)}$.

Investigating the cardiovascular risk factors of nursing students enables internal debates, directs education professionals and managers and, above all, alerts students about the magnitude of the problem and the need for early detection and management of cardiovascular risk. Moreover, it highlights the importance of building disease prevention programs and promoting quality of life, seeking to reduce rates of cardiovascular diseases such as CAD.

\section{OBJECTIVES}

To identify and discuss the main risk factors for coronary artery disease, observed in nursing students.

\section{METHODS}

\section{Ethical aspects}

This study respects the precepts of Resolution 466/12 of the Brazilian National Health Council (Conselho Nacional de Saúde). The project was approved by the Research Ethics Committee of Universidade Federal Fluminense (UFF).

\section{Design}

This is a cross-sectional observational study guided by STROBE ${ }^{(9)}$.

\section{Study site}

This research took place at UFF School of Nursing, located in the city of Niterói/RJ, in which workload was 5,440 hours, distributed in nine semesters (periods) at data collection time. Data collection took place from May to June 2018.

\section{Population or sample}

Considering a highly homogeneous local population of 372 undergraduate nursing students at a public college in Niterói/RJ, the sample calculation, performed by the WinPepi 11.65 program, estimated a sample of 85 students. For this, a $95 \%$ confidence level was considered, an acceptable difference of 10 per 100, an assumed rate of 50 per 100 and a sample loss of $10 \%$.

Sample was randomized, in order to reduce the selection bias and increase accuracy of study results. To this end, a list was created with the name of each student enrolled in a nursing course from the first to the ninth period, over 20 years old, who received a sequential number for identification. Randomization was carried out through the website www.randomization.com.

\section{Inclusion and exclusion criteria}

Undergraduate students in nursing enrolled between the first and ninth periods, aged 20 years and older, were included in order to meet the PROCAM algorithm criteria, which estimates the risk of a coronary event only between 20 and 75 years old. Students with closed enrollment and who did not complete all stages of study were excluded. 


\section{Study logistics}

This study was carried out in three stages. In the first stage, an invitation was sent to students selected by randomization to participate in the study. Students who agreed to participate in the study signed the Informed Consent Form and filled out an identification instrument with name, period, telephone number and email.

In the second stage, a questionnaire prepared by the authors with semi-structured questions containing identification data and on presence of cardiovascular risk factors was applied. Another five self-applicable and validated instruments for use in Brazil were applied digitally by Google Forms (access link sent by email and WhatsApp). Students who requested received the instruments in print.

In the third stage, systemic blood pressure (SBP) was measured, waist circumference, weight and height were measured to calculate the Body Mass Index (BMI), in a private room at the school of nursing, guaranteeing privacy at assessment.

To measure SBP, participants were individually accommodated in a reserved space, free of noise and stressors, seated, with uncrossed legs, feet flat on the floor, back leaning on the chair and relaxed, arm at heart level, supported, with palm of the hand facing upwards. The positioning of the stethoscope's cuff and diaphragm was performed in accordance with the $7^{\text {th }}$ Brazilian Guideline on Hypertension recommendations ${ }^{(10)}$. SBP was determined by auscultation of the first sound (Korotkoff phase I) and diastolic blood pressure (DBP) in the disappearance of sounds (Korotkoff phase V). At least two measurements were made, with an interval of one minute. Values $\leq 120$ for SBP and $\leq 80 \mathrm{mmHg}$ for DBP were considered normal ${ }^{(10)}$.

Waist circumference was measured at the midpoint between the lower costal margin and the iliac crest. Hip measurement was obtained, in its largest diameter, with the measuring tape passing over the greater trochanters. The cutoff point was 102 $\mathrm{cm}$ for men and $88 \mathrm{~cm}$ for women ${ }^{(11)}$.

After all stages of data collection, stratification of cardiovascular risk factors was measured by assessing the instruments applied and students' initial sociodemographic and clinical profiles, observing the PROCAM algorithm. Developed in $2002^{(12)}$, updated in $2007^{(13)}$ and in the electronic domain (https://www.assmannstiftung.de/procam-tests/) $)^{(14)}$, it estimates the risk of a coronary event in 10 years, through a score adjusted by age range, ranging from 20 to 75 years.

\section{Quantitative variables}

The sociodemographic variables surveyed were age, sex, self-declared color, marital status, undergraduate cycle, personal monthly income and family monthly income. Clinical variables were alcohol consumption, tobacco use, personal history and family diseases (up to three generations) ${ }^{(15)}$ hypertension (HP), diabetes mellitus (DM), dyslipidemia, and CAD, time in hours of daily study, sleep pattern (hours slept per day).

Sedentary behavior was measured by the International Physical Activity Questionnaire (IPAQ), proposed by the World Health Organization (WHO) since 1998. It consists of eight questions related to frequency, duration and intensity of physical activities developed daily, with the following classifications: (1) sedentary: does not practice physical activity; (2) insufficiently active: practices activities for up to 10 continuous minutes per week; (3) active: intense activity 3 times or more per week, 20 minutes or more, daily, or intermediate level activity 5 times or more during the week in at least 30 minutes daily, or, any activity for 5 days or more, weekly, for at least 150 minutes weekly; (4) very active: performs intense activity 5 days or more during the week for 30 minutes or more per day, or intense activity 3 days or more per week, over or equal to 20 minutes per day, plus intermediate activity and/or walking 5 days or more per week for a minimum of 30 minutes per day ${ }^{(16)}$.

Alcoholism was measured by the Alcohol Use Disorders Identification (AUDIT), developed by WHO in 2001, through ten questions answered by the participants who declare alcohol consumption. Each alternative has a score of 0 to 4, totaling the maximum value of 40 points, classified as low risk or abstainers (0 to 7 points), high risk (8 to 15 points), high risk (16 to 19 points) and probable dependence (20 or more points) ${ }^{(17)}$.

Stress was assessed using the Stress Assessment Among Nursing Students (AEEE - Avaliação de Estresse em Estudantes de Enfermagem) scale, for 30 items grouped into the following six domains: (1) Carrying out practical activities (items 4, 5, 7, 9, 12 and 21); (2) Professional communication (6, 8, 16 and 20); (3) Time management (3, 18, 23, 26 and 30); (4) Environment (11, 22, 24 and 29); (5) Professional training (1, 15, 17, 19, 25 and 27); (6) Theoretical activity $(2,10,13,14$ and 28). Each item has answers ranging from 0 to 3, in which 0 refers to "I don't experience the situation", and 3, "I feel very stressed with the situation". Stress levels were classified as low, medium, high and very high, independently, according to the cutoff points indicated by the author, for each of the domains ${ }^{(18)}$.

Smoking was assessed by the Fagerström Test for Nicotine Dependence (FTND) in those who declared themselves to be smokers. It consists of six questions, each with a score, and the sum of the points indicates the degree of nicotine dependence: very low (0-2), low (3-4), mean (5), high (6-7) and very high (8-10)(19).

Eating habits were measured by the instrument called "How is your eating habits?", which was proposed by $\mathrm{MoH}$ composed of 18 questions, in which each question ranges from 0 to 4 . The test result is obtained with the total sum of points. Up to 28 points: inadequate dietary pattern; from 29 to 42 points: dietary pattern that requires attention; 43 points or more: adequate dietary pattern ${ }^{(20)}$.

In order to stratify cardiovascular risk, in addition to these assessment instruments, the variables gender, systolic blood pressure, presence of $\mathrm{DM}, \mathrm{BMI}$, smoking and history of family diseases were considered, included in the sociodemographic and clinical questionnaire. All these data were compared with the PROCAM algorithm, which measures the risk of a coronary event in 10 years. It consists of seven items, in which specific points are assigned for sex, systolic blood pressure value, presence of DM or Hgt> $120 \mathrm{mg} / \mathrm{dl}, \mathrm{BMI}\left(\mathrm{kg} / \mathrm{m}^{2}\right)$, use of medicines to increase blood pressure (self-reported), smoking, heart attack by parents, grandparents or siblings before the age of 60 .

The score varies between zero ( 0 ) and 32 points, with the highest risk related to the highest score. The result is distributed by age group and classified in colors: green - low risk of coronary 
Risk factors for coronary artery disease in nursing students Moraes HSC, Flores PVP, Cavalcanti ACD, Figueiredo LS, Tinoco JMVP.

event in the next 10 years; yellow - moderate risk, above $10 \%$ in 10 years; red - high risk (over $20 \%$ in 10 years in PROCAM test) ${ }^{(13-14)}$.

\section{Analysis of results, and statistics}

Descriptive analysis included measures of mean or median, standard deviation or interquartile range for numerical variables. Considering that the sample has a sample number above 50, Shapiro-Wilk test was chosen to assess normality ${ }^{(21)}$, considering $p<0.05$. Categorical variables were measured by simple frequency and percentage.

To check the association of pattern dietary measures, frequency of alcohol consumption, very high stress with the study cycles of an undergraduate nursing course, chi-square test or Fisher's exact test was used. To assess waist circumference association with BMI classifications, Anova (one-way) or Kruskal-Wallis test was used. A p value of 0.05 was considered for statistical significance.

\section{RESULTS}

Two hundred and twelve students over 20 years old were randomized and invited, 102 of whom did not respond to the invitation. Of the 110 students who agreed to participate in the study, all of them met the eligibility criteria, thus composing the final sample analyzed. Among the 110 students, there was a loss due to lack of completion in the questionnaires: dietary pattern (109); risk of coronary event - PROCAM (104); BMI calculation (104).

For this study, the undergraduate periods were organized in cycles, with nursing students inserted in basic cycle, which comprises $1^{\text {st }}, 2^{\text {nd }}$ and $3^{\text {rd }}$ periods; transition cycle, which covers $4^{\text {th }}, 5^{\text {th }}$ and $6^{\text {th }}$ periods; professional cycle, consisting of $7^{\text {th }}, 8^{\text {th }}$ and $9^{\text {th }}$ periods. The sociodemographic and clinical profile of the sample studied is shown in Table 1. It is noteworthy that, according to Shapiro-Wilk test, all variables were normally distributed.

Table 2 shows AEEE, PROCAM Quick Check score, physical activity (IPAQ), alcohol consumption pattern (AUDIT), FTND and dietary pattern. It is noticed that most students are active or very active, with inadequate dietary pattern and low-risk or abstainer alcohol consumption. High stress level is related to professional training (Dom_5). Event risk had an average score of 3.50 (0.2510.75), with a minimum of zero and a maximum of 32 . It should be noted that all variables, with the exception of the food pattern questionnaire, had an abnormal distribution.

Concerning AEEE, the domains were analyzed, in isolation, and the results were presented by the four levels of stress proposed in the scale: low, medium, high and very high. A very high level of stress was identified in the variables related to the environment (20\%), professional training (20\%), professional communication (19.1\%) and carrying out practical activities (16.4\%).

The dietary pattern of nursing students varied between intermediate 55 (50.5\%) and poor 54 (49.5\%), with a mean of $28.39 \pm 5.47$ points. Regarding participants'alcoholism profile, the questionnaire was only answered by students who reported consuming alcohol. It was found that 20 (32.3\%) of the interviewees carried out risky consumption and 01 (1.6\%) high-risk consumption, suggestive of the onset of disorders related to alcohol consumption. On the other hand, 41 (66.1\%) have low risk or teetotaler consumption and none was dependent.
Table 1 - Clinical and sociodemographic profile of nursing students ( $N=110)$, Niterói, Rio de Janeiro, Brazil, 2018

\begin{tabular}{|c|c|}
\hline Variables & $N=110$ \\
\hline Age (years) & $22.03 \pm 3.63^{*}$ \\
\hline Sex (Female) & $88(80)^{\dagger}$ \\
\hline $\begin{array}{l}\text { Self-declared color } \\
\text { Mixed-ethniticity } \\
\text { White } \\
\text { Black }\end{array}$ & $\begin{array}{l}29(26.4)^{\dagger} \\
68(61.8)^{\dagger} \\
13(11.8)^{\dagger}\end{array}$ \\
\hline $\begin{array}{l}\text { Marital status } \\
\text { Single } \\
\text { Married }\end{array}$ & $\begin{array}{c}104(94.5)^{\dagger} \\
6(5.5)^{\dagger}\end{array}$ \\
\hline $\begin{array}{l}\text { Undergraduate cycle } \\
\text { Basic }\left(11^{\text {st }}, 2^{\text {nd }} \text { and } 3^{\text {rd }} \text { periods }\right) \\
\text { Transition }\left(4^{\text {th }}, 5^{\text {th }} \text { and } 6^{\text {th }} \text { periods }\right) \\
\text { Professional }\left(7^{\text {th }}, 8^{\text {th }} \text { and } 9^{\text {th }} \text { periods }\right)\end{array}$ & $\begin{array}{l}25(22.7)^{\dagger} \\
54(49.1)^{\dagger} \\
31(28.2)^{\dagger}\end{array}$ \\
\hline $\begin{array}{l}\text { Personal monthly income } \\
\text { Less than } 01 \text { minimum wage } \\
\text { From } 01 \text { to } 03 \text { minimum wages } \\
\text { Above } 03 \text { minimum wages }\end{array}$ & $\begin{array}{c}88(81.5)^{\dagger} \\
17(15.7)^{\dagger} \\
3(2.8)^{\dagger}\end{array}$ \\
\hline $\begin{array}{l}\text { Family monthly income } \\
\text { From } 01 \text { to } 03 \text { minimum wages } \\
\text { Above } 03 \text { minimum wages }\end{array}$ & $\begin{array}{l}91(82.7)^{\dagger} \\
19(17.2)^{\dagger}\end{array}$ \\
\hline Alcohol consumption & $62(56.4)^{\dagger}$ \\
\hline Tobacco use & $4(3.6)^{\dagger}$ \\
\hline Family history of $\mathrm{HP}^{\ddagger}$ & $91(82.7)^{\dagger}$ \\
\hline Family history of $\mathrm{DM}^{\S}$ & $71(64.5)^{+}$ \\
\hline Family history of CAD\| & $35(31.8)^{\dagger}$ \\
\hline $\mathrm{HP}^{\ddagger}$ & $1(0.9)^{\dagger}$ \\
\hline $\mathrm{DM}^{\S}$ & $1(0.9)^{\dagger}$ \\
\hline CAD\| & $0(0)^{+}$ \\
\hline $\begin{array}{l}\text { Hours of study } \\
\text { Weekdays } \\
\text { Weekend }\end{array}$ & $\begin{array}{l}3.05 \pm 1.45^{*} \\
4.62 \pm 1.00^{*}\end{array}$ \\
\hline $\begin{array}{l}\text { Hours of sleep } \\
\text { Less than } 3 \text { hours/day } \\
3-7 \text { hours/day } \\
8 \text { hours a day } \\
\text { More than } 8 \text { hours a day }\end{array}$ & $\begin{array}{c}12(10.9 \%) \\
88(80 \%) \\
10(9.1 \%) \\
0(0 \%)\end{array}$ \\
\hline Systolic Blood Pressure & $112.79 \pm 12.59^{*}$ \\
\hline Diastolic Blood Pressure & $74.59 \pm 10.32^{*}$ \\
\hline $\begin{array}{l}\text { Anthropometric assessment } \\
\text { Height } \\
\text { Body Mass Index } \\
\text { Waist circumference }(\mathrm{cm}) \\
\text { Man } \\
\text { Woman }\end{array}$ & $\begin{array}{c}1.65 \pm 0.74^{*} \\
23.90 \pm 5.18^{*} \\
77.80 \pm 11.03^{*} \\
86.14 \pm 9.237^{*} \\
75.69 \pm 10.47^{*}\end{array}$ \\
\hline
\end{tabular}

Association between body fat distribution and central adiposity was incorporated into the study. According to the Brazilian Obesity Association (2016), the combination of waist circumference (WC) measurement with BMI can offer a combined method for risk assessment, helping to reduce the limitations of each of the isolated assessments for detecting cardiometabolic risk factors in both sexes.

Even though higher values are concentrated in the healthy weight range, it is possible to highlight overweight in both men and women. In the group with the highest risk, the highest rates are concentrated in the female population, with obesity associated with a high WC measure (8.65\%), as opposed to men (1.92\%), considering the reference values determined by the WHO for variable calculation (Table 4). 
Table 2 - Assessment of nursing students in nursing student stress questionnaires, AUDIT, food pattern questionnaire, IPAQ and PROCAM $(\mathrm{N}=110)$, Niterói, Rio de Janeiro, Brazil, 2018

\begin{tabular}{lc}
\hline Variables & $\mathbf{N}=\mathbf{1 1 0}$ \\
\hline Stress & \\
$\quad$ Practical activities (Dom_1) & $10.90 \pm 3.82^{*}$ \\
Professional communication (Dom_2) & $6.0 \pm 2.99^{*}$ \\
Time management (Dom_3) & $11.44 \pm 2.51^{*}$ \\
Environment (Dom_4) & $6.84 \pm 3.85^{*}$ \\
Professional training (Dom_5) & $11.62 \pm 3.42^{*}$ \\
Theoretical activity (Dom_6) & $10.50 \pm 2.38^{*}$ \\
AUDIT (alcohol consumption) & $6(2-9)^{\dagger}$ \\
Food pattern questionnaire & $28.39 \pm 5.47^{*}$ \\
IPAQ (physical activity) & $3(3-4)^{\dagger}$ \\
PROCAM & $3.50(0.25-10.75)^{\dagger}$ \\
\hline Note**Mean and standard deviation; ${ }^{+}$median
\end{tabular}

Table 3 - Nursing student stress by domain ( $=110)$, Niterói, Rio de Janeiro, Brazil, 2018

\begin{tabular}{|c|c|c|c|c|}
\hline \multirow{2}{*}{ Variables } & \multicolumn{4}{|c|}{ Level of stress $\mathbf{N}(\%)$} \\
\hline & Low & Medium & High & Very high \\
\hline Carrying out practical activities & $30(27.3)$ & $40(36.4)$ & $22(20)$ & $18(16.4)$ \\
\hline Professional communication & $40(36.4)$ & $21(19.1)$ & $28(25.5)$ & $21(19.1)$ \\
\hline Time management & $35(31.8)$ & $35(31.8)$ & $29(26.4)$ & $11(10)$ \\
\hline Environment & $62(56.4)$ & $18(16.4)$ & $8(7.3)$ & $22(20)$ \\
\hline Professional training & $32(53.3)$ & $8(13.3)$ & $8(13.3)$ & $12(20)$ \\
\hline Theoretical activity & $37(33.6)$ & $30(27.3)$ & $32(29.1)$ & $11(10)$ \\
\hline
\end{tabular}

Table 5 reveals higher risk consumption (17.74\%) and high-risk consumption (1.61\%) of alcoholic beverages among those who are part of the transition cycle $\left(4^{\text {th }}, 5^{\text {th }}\right.$ and $6^{\text {th }}$ period $)$ of the studied sample. The association between the factors analyzed and the students' undergraduate cycle highlights that the highest stress levels (11.81\%), alcoholism (17.74\%) and inadequate dietary pattern (24.77\%) were found in transition cycle. In relation to stress, the relationship between very high stress and the domains proposed by the stress scale in nursing students was highlighted.

Regarding tobacco use, FTND was applied to measure the degree of nicotine dependence of students who declared to use tobacco. As a result, only 4 (3.63\%) participants claimed to be smokers. Among them, all obtained a minimum score (zero) in the six questions covered by the questionnaire.

\section{DISCUSSION}

This study identified a relatively young population with relevant aspects with regard to cardiovascular risk factors. Among the findings, stress, alcohol consumption and food inadequacy of the college population are highlighted. It is also worth noting the concentration of such risk factors among participants in transition cycle.

Different phases of life can influence poor diet and consequent weight gain, such as the beginning of professional life, in which lack of time leads individuals to interrupt sports and reduce energy expenditure and eat meals in a short space of time ${ }^{(11)}$.

Table 4 - Association of the waist circumference of nursing students with Body Mass Index classifications proposed by the World Health Organization ( $N$ = 104), Niterói, Rio de Janeiro, Brazil, 2018

\begin{tabular}{|c|c|c|c|c|c|c|}
\hline \multirow{2}{*}{ BMI $\left(\mathbf{k g} / \mathbf{m}^{2}\right)$} & \multicolumn{3}{|c|}{ Female $(n=83)$} & \multicolumn{3}{|c|}{ Male $(n=21)$} \\
\hline & $N(\%)$ & Waist Circumference $(\mathrm{cm})^{*}$ & $p$ value $^{\ddagger}$ & $n(\%)$ & Waist Circumference $(\mathrm{cm})^{\dagger}$ & $p$ value ${ }^{\ddagger}$ \\
\hline Low weight & $8(7.69)$ & $64(62.25-68)^{*}$ & & $2(1.92)$ & $72.50 \pm 0.70^{+}$ & \\
\hline Healthy weight & $55(52.88)$ & $72(68-77)^{*}$ & & $7(6.73)$ & $80.71 \pm 6.96^{\dagger}$ & \\
\hline Overweight & $11(10.58)$ & $80(77-86)^{*}$ & $0.001^{\ddagger}$ & $10(9.62)$ & $91.10 \pm 7.14^{\dagger}$ & $0.003^{\ddagger}$ \\
\hline Obesity & $9(8.65)$ & $97(92-103.50)^{*}$ & & $2(1.92)$ & $94.00 \pm 2.82^{+}$ & \\
\hline
\end{tabular}

Note: *Median/Anova; +Mean and standard deviation; $¥$ Kruskal-Wallis test.

Table 5 - Assessment of dietary pattern, alcohol consumption and very high stress per cycle of an undergraduate nursing course, Niterói, Rio de Janeiro, Brazil, 2018

\begin{tabular}{|c|c|c|c|c|}
\hline Variables & Basic cycle* & Transition* & Professional cycle* & $\boldsymbol{p}$ value $^{\dagger}$ \\
\hline \multicolumn{5}{|l|}{ Food pattern $(n=109)$} \\
\hline Bad & $15(13.76)$ & 27 (24.77) & $12(11)$ & \multirow{3}{*}{0.334} \\
\hline Intermediate & $10(9.17)$ & $27(24.77)$ & $18(16.51)$ & \\
\hline Good & - & - & - & \\
\hline \multicolumn{5}{|l|}{ AUDIT $(n=62)$} \\
\hline Low risk/teetotaler & $10(16.12)$ & $20(32.25)$ & $11(17.74)$ & \multirow{4}{*}{0.880} \\
\hline Risk consumption & $4(6.45)$ & $11(17.74)$ & $5(8.06)$ & \\
\hline Harmful & - & $1(1.61)$ & - & \\
\hline Dependent & - & - & - & \\
\hline \multicolumn{5}{|l|}{ Very high stress $(n=95)$} \\
\hline Practical activity & $1(0.90)$ & $12(10.90)$ & $5(4.54)$ & 0.002 \\
\hline Communication & $1(0.90)$ & $12(10.90)$ & $8(7.27)$ & 0.001 \\
\hline Time management & $2(1.81)$ & $6(5.45)$ & $3(2.72)$ & 0.697 \\
\hline Environment & $1(0.90)$ & $13(11.81)$ & $8(7.27)$ & 0.123 \\
\hline Professional training & - & $6(5.45)$ & $6(5.45)$ & 0.013 \\
\hline Theoretical activity & $2(1.81)$ & $6(5.45)$ & $3(2.72)$ & 0.939 \\
\hline \multicolumn{5}{|l|}{ PROCAM $(n=104)$} \\
\hline PROCAM (0 to 8) & $15(14.42)$ & 34 (32.69) & $26(25)$ & \multirow{4}{*}{0.080} \\
\hline PROCAM (9 to 16$)$ & $5(4.80)$ & $16(15.38)$ & $3(2.88)$ & \\
\hline PROCAM (17 to 24 ) & $2(1.92)$ & - & $1(0.91)$ & \\
\hline PROCAM (25 to 32 ) & & $2(1.92)$ & - & \\
\hline
\end{tabular}


Risk factors for coronary artery disease in nursing students Moraes HSC, Flores PVP, Cavalcanti ACD, Figueiredo LS, Tinoco JMVP.

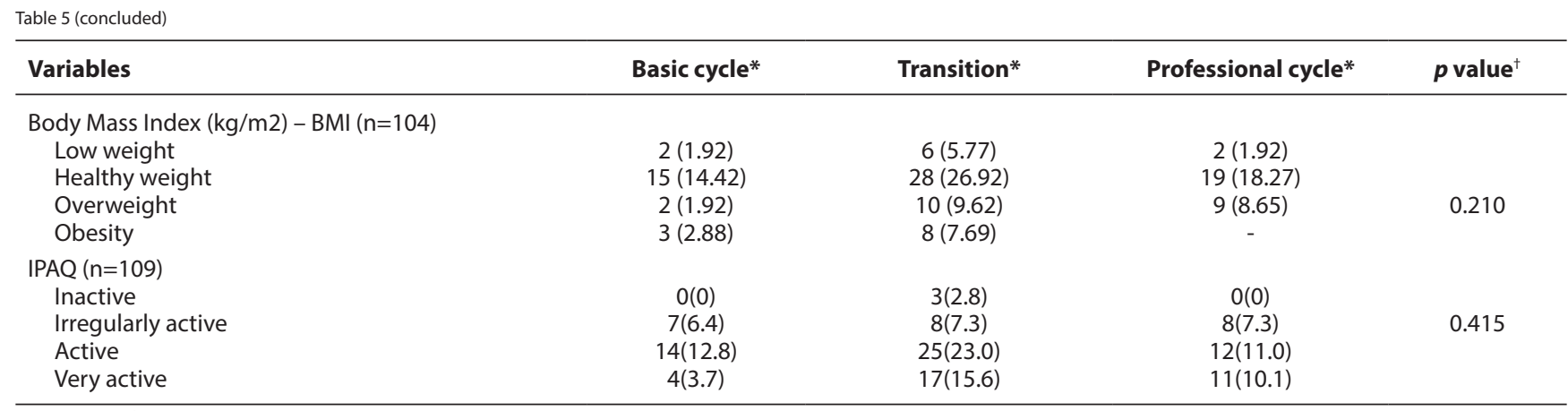

Note: ${ }^{*} n(\%) ;{ }^{+}$chi-square test.

Admission to the college can represent the moment when young people leave their families, inducing them to opt for processed food consumption, due to its practicality. The negligence of this student in caring for his own food stems, for the most part, from the demand for time and dedication required by the college ${ }^{(22)}$.

A survey of risk factors for cardiovascular disease in 286 nursing students at a public college in Mexico ${ }^{(23)}$ found a comparatively young group (mean of 20 years), whose eating pattern is better in relation to the quality of the food consumed, when compared to students in this study.

Individual and/or family monthly income can influence the quality of students' food. Part of students live alone or in republics and, often, with little family allowance, as seen in the family income data of this study. Furthermore, many students mostly depend on their own income, through scholarships provided by the college or funding agencies. In this light, a study with 205 male college students identified that substitution of foods of low nutritional value with more recommended foods for a good diet are related to both individual and family income of students $^{(24)}$.

WC data show that, in this study, similar to the findings of a 2015 Chilean study ( $86.87 \mathrm{~cm}$ in men and $85.82 \mathrm{~cm}$ in women), men have WC values $(86.14 \pm 9.237)$ higher than those women $(75.69 \pm 10.47 \mathrm{~cm})^{(25)}$.

However, isolated BMI assessment does not seem to have a predictive character for cardiovascular risk. A study that assessed the predictive value of the taper index, BMI and WC for CAD found that none of the anthropometric measures was sufficient to diagnose CAD or estimate mortality rate in the general population ${ }^{(26)}$. Thus, the present study used a combined assessment of BMI with WC, as recommended by ABESO(11).

The outcome of cardiovascular assessment in the 110 nursing students reveals an increased risk for cardiovascular disease in both sexes in the overweight group. Linked to BMI, WC values are between 94 and $102 \mathrm{~cm}(91.10 \pm 7.14 \mathrm{~cm})$ in men, and between 80 and $88 \mathrm{~cm}(77-86 \mathrm{~cm})$ in women; high risk for men with obesity, in which there is a BMI/WC ratio whose circumference is between 94 and $102 \mathrm{~cm}(94.00 \pm 2.82 \mathrm{~cm})$ and very high risk for obese women, a condition in which, in addition to elevated $\mathrm{BMI}(\geq 30), \mathrm{WC}$ is $>88 \mathrm{~cm}(92-103.50 \mathrm{~cm})^{(11)}$.

A cross-sectional study assessed gender disparity in perceived body weight, BMI, weight satisfaction and the role of depression among 241 medical students and 213 nursing undergraduates at a college in southern India ${ }^{(27)}$. The results show that the BMI for men was substantially higher than that for women ( $t=5,403$, $p<0.001$ ), which corroborates the present analysis. Both sexes showed signs of eating disorders, with compulsory eating habits present in $48.2 \%$ of women and $41.2 \%$ of men.

Another study with 52 students from an American college found that the time of total physical activity (minutes/week) did not change over the undergraduate course time. Walking was the most reported activity, followed by vigorous activity and, finally, moderate activity. On average, students were able to maintain high levels of physical activity, recommended for long-term health benefits, which corroborates the findings of this study, in which the population analyzed obtained a mean score of 3 (3-4) on IPAQ. This indicates that most nursing students are active (3 points) or very active (4 points) regarding physical activity ${ }^{(28)}$.

Regarding physical activity, the highest rates were observed among students in the transition cycle. The study shows that, although most students practice some physical activity, the regularity of this activity is not adequate in all groups, in the different undergraduate periods.

A study assessed anxiety, depression, daily physical activity, work and physical fitness levels in 62 students, by analyzing IPAQ. It was documented, in both sexes, that the activities performed by the studied nursing students are predominantly performed in the sitting resting position $(2,052 \pm 1,131.2$ minutes/week and $2,139.1 \pm 948.9$ minutes/week, respectively) ${ }^{(29)}$. Another, with 100 students, with IPAQ identified that $20 \%$ of subjects were classified as inactive, $38 \%$ as irregularly active, $17 \%$ as active and $25 \%$ as very active ${ }^{(30)}$.

Stress among students represents one of the most relevant cardiovascular risk factors, as evidenced by this study. Among the different contexts experienced by nursing students, professional training is responsible for causing high stress in that population ${ }^{(18)}$.

Nursing students are routinely exposed to stressful situations. These situations are induced by factors such as scientific and technological development, the greater complexity of the teaching/learning process, the contexts of practice, the dubious experience between what they learn in theory and the reality they are faced with, almost permanent submission to assessment methods, with high demand for assessments and exhaustive academic papers ${ }^{(31)}$.

Nursing is a course that requires constant attention, starting from the point that this stage is crucial for students to develop 
skills aimed at their professional practice, in a potentially stressful condition. Dealing with human life gives the teaching-learning process a challenging character, since an error can culminate in injuries, damages or even the death of patients ${ }^{(32)}$.

A semester taken at college seems to be associated with levels of psychological disorders, such as stress. The present analysis shows that the highest numbers of nursing students with stress are between the $4^{\text {th }}, 5^{\text {th }}$ and $6^{\text {th }}$ periods. These periods, in undergraduate nursing, represent introduction to theoreticalpractical activities, requiring greater technical competence and the ability to integrate the knowledge acquired in the basic cycle's courses to professional practice in internship fields. Practical activity, communication and the environment were detected, in this study, as predominant stressors.

Similar results were obtained in another study conducted in northeastern Brazil with 167 nursing students. Comparisons between stress levels and undergraduate periods showed that the highest stress levels were observed from the $1^{\text {st }}$ to the $5^{\text {th }}$ period, when compared to other periods, such as the $8^{\text {th }}$, whose level is moderate. It was also found that the most significant stress factors were practical activity, professional communication and theoretical activity ${ }^{(33)}$.

The impact of practical activities on the psychological status of students was perceived in a randomized clinical trial conducted in Brazil with 52 nursing students in 2017, to assess and compare the perception of stressful factors of nursing students before and after a clinical simulation of high Fidelity. There was a considerable increase in the perception of factors related to lack of competence, not controlling the relationship with patients, emotional involvement and contact with suffering as stressors for students after a simulation ${ }^{(30)}$.

The sleep pattern of students is another factor to be considered. Sleep disorders affect the individual's quality of life, inducing changes in mood, tiredness, fatigue, memory deficit and tachycardia, in addition to disorders that, in the medium term, can lead to a reduction in the quality of work performance and in interpersonal relationships, and, in the long term, cause health problems. Therefore, assessing the quality of sleep makes it possible to subsidize health promotion and disease prevention $^{(34)}$.

In this study, $80 \%$ of students reported having between 3 and 7 hours of sleep, while $10.9 \%$ reported sleeping less than 3 hours a night and only $9.1 \%$ reported being able to sleep 8 hours a night. Of the 110 students assessed, none (0\%) reported having more than 8 hours of sleep. According to the National Sleep Foundation (2015), for young adults ( 18 - 25 years) adults ( 26 - 64 years), the ideal sleep pattern is between 7 and 9 hours a day, being inappropriate for this age group. sleep for less than 6 hours or more than 11 hours a night.

Sleep quality analysis among nursing students at a public college in southern Brazil, carried out with 185 students, concluded that $54.6 \%$ of students sleep for at least 6 hours, while $23 \%$ are able to sleep for longer than 7 hours and 5\% sleep for less than 5 hours daily ${ }^{(34)}$.

In a study carried out among 277 medical students at Universidade Federal da Paraíba, it was observed that, on average, the number of hours slept was 5 hours and 50 minutes per night. A census of 1,865 college students at Universidade Federal de Pelotas, to investigate sleep disorders, found that the mean sleep duration of students on school days was 6.5 hours, and on weekends, the mean duration of sleep for students was 8.1 hours $^{(35)}$.

Alcohol and tobacco consumption are also present in the routine of students. Alcoholism was reported by $56.4 \%$ of participants. However, tobacco use was insignificant, with consumption declared by only 4 (3.63\%) participants. Of these, none presented a score on FTND that indicated harmful consumption of substance. Thus, it is inferred that a small portion of the studied population has a smoking habit and among these, none of them carry out the harmful consumption of the substance, therefore, there is no degree of nicotine dependence among the nursing students analyzed.

In agreement with these data, a cross-sectional Brazilian study found a similar discrepancy between the prevalence of alcohol and tobacco consumption among 286 health students, in which alcohol consumption was reported by $66.4 \%$ of students, and tobacco use was reported by only $5 \%$ of the sample ${ }^{(36)}$.

The AUDIT questionnaire found harmful alcohol consumption in $32.3 \%$ of students and high-risk consumption in $1.6 \%$. A Brazilian study carried out in 2017, with 163 nursing students, found that alcohol consumption was at risk in $48.5 \%$ and harmful use (high risk) in $19 \%$ of the studied sample, with the highest prevalence of consumption in the initial semesters of the course $\mathrm{e}^{(37)}$.

A combined analysis of cardiovascular risk factors using PROCAM Quick Check estimated an overall score of approximately $3.50(0.25-10.75)$ points in a sample of 104 nursing students, with $p$ value $<0.001$; 0 was the minimum value and 32 the maximum points added by the score. As for the PROCAM score by period, transition cycle once again gains emphasis, concentrating the highest scores, in which $32.69 \%$ added 0 to 8 points.

When assessing the total score of the sample, it appears that none of the students has a significant risk for a cardiovascular event in the next 10 years, taking into account that, in PROCAM, moderate to high risk can be classified only in individuals over the age of 31 years, which, in this study, represent only $2.88 \%$ of a predominantly young population.

The greater effectiveness of PROCAM for stratifying low-risk patients without overestimating CVD risk is currently being considered as a standard score for cardiovascular prognosis in Latin American countries such as Colombia(38).

However, no studies were found that address the use of PROCAM as a predictor score for cardiovascular risk in the young population, especially among students, which reinforces the need to develop research that can test and validate accurate methods for the analysis and prognosis of cardiovascular health in individuals at an early age. In addition, studies are needed to assess the accuracy of PROCAM in the Brazilian population.

\section{Study limitations}

This study is limited by the sample and the failure to perform laboratory tests, making the PROCAM Health Check application 
unfeasible. It is also limited by the failure to measure the waist $\mathrm{x}$ hip ratio.

\section{Contributions to nursing}

Identifying students' habits during undergraduate courses offers important data about a young population, given the challenge of insertion in the labor market and transition to adult life. Thus, it is proposed to build interventions and preventive actions to be carried out to reduce the risks and problems for CAD among nurses, contributing to an adequate management of the cardiovascular health of these professionals.

\section{CONCLUSIONS}

Nursing students, although at low risk for CAD, according to PROCAM Quick Check score, have relevant cardiovascular risk factors such as stress, inadequate diet and risk of alcohol consumption.

Students' stress, alcohol consumption and food inadequacy show a significant increase in the course's transition cycle $\left(4^{\text {th }}, 5^{\text {th }}\right.$ and $6^{\text {th }}$ periods); this stage represents the end of the biomedical cycle, involving generalist courses to specific fields of health, starting with theoretical and practical activities inherent to nurses, promoting important curricular changes that culminate in new perspectives and desires in students.

\section{REFERENCES}

1. Ministério da Saúde (BR). DATASUS. Informações de Saúde (TABNET) [Internet]. Brasília (DF); 2018 [cited 2018 Mar 20]. Available from: http:// tabnet.datasus.gov.br/cgi/tabcgi.exe?sih/cnv/niuf.def.

2. Carvalho CA, Fonseca PCA, Barbosa JB, Machado SP, Santos AM, Silva AAM. The association between cardiovascular risk factors and anthropometric obesity indicators in university students in São Luís in the State of Maranhão, Brazil. Ciênc. Saúde Colet. 2015;20(2):479-90. doi: 10.1590/1413-81232015202.02342014

3. Costa IFAF, Medeiros CCM, Costa FDAF, Farias CRL, Souza DRA, Adriano WS, et al. Adolescents: behavior and cardiovascular risk. J Vasc Bras. 2017;16(3):205-13. doi: 10.1590/1677-5449.011816

4. Bloch KV, Cardoso MA, Sichieri R. Study of Cardiovascular Risk Factors in Adolescents (ERICA): results and potentiality. Rev Saúde Pública. 2016;50(supl1):2s. doi:10.1590/S01518-8787.201605000SUPL1AP

5. Coelho AC, Lopes JL, Santos VB, Barros ALBL. Risk factors of coronary artery disease in family members living with acute coronary patients. REME Rev Min Enferm. 2016;20:e963. doi: 10.5935/1415-2762.20160033

6. Faludi AA, Izar MCO, Saraiva JFK, Chacra APM, Bianco HT, Afiune Neto A, et al. Atualização da Diretriz Brasileira de Dislipidemias e Prevenção da Aterosclerose - 2017. Arq Bras Cardiol. 2017;109(2Supl.1):1-76. doi: 10.5935/abc.20170121

7. Santos JS, Patrício ACFA, Alves KL, Albuquerque KF, Pereira IL, Félix IVB. Cardiac risk assessment amongst undergraduate nursing students. Rev Min Enferm. 2015;19(4):842-7. doi: 10.5935/1415-2762.20150065

8. Paulitsch R, Dumith SC, Susin LRO. Simultaneity of behavioral risk factors for cardiovascular disease in university students. Rev Bras Epidemiol. 2017;20(4):624-35. doi: 10.1590/1980-5497201700040006

9. Malta M, Cardoso LO, Bastos FI, Magnanini MMF, Silva CMFP. STROBE initiative: guidelines on reporting observational studies. Rev Saúde Pública 2010;44(3):559-65. doi: 10.1590/S0034-8910201000030002

10. Sociedade Brasileira de Cardiologia. 7a Diretriz Brasileira de Hipertensão Arterial [Internet]. 2016, 83 p. [cited 2020 May 20]. 107(3Supl.3):183. Available from: http://publicacoes.cardiol.br/2014/diretrizes/2016/05_HIPERTENSAO_ARTERIAL.pdf

11. Associação Brasileira para o Estudo da Obesidade e da Síndrome Metabólica. Diretrizes brasileiras de obesidade. [Internet]. $4^{\mathrm{a}}$ ed. São Paulo: A Associação; 2016, 188 p. [cited 2017 Oct 21]. Available from: http://www.abeso.org.br/uploads/downloads/92/57fccc403e5da.pdf

12. Assmann MDG, Cullen FRCP, Schulte FRCPI. Simple Scoring Scheme for Calculating the Risk of AcuteCoronary Events Based on the 10-Year Follow-Up of the Prospective Cardiovascular Münster (PROCAM) Study. 2002. American Heart Association. Circulation. 2002;105(3:310-315. doi: $10.1161 /$ hc0302.102575

13. Assmann G, Schulte H, P Cullen P, Seedorf U. Assessing Risk of Myocardial Infarction and Stroke: New Data From the Prospective Cardiovascular Münster (PROCAM) Study. European J Clin Investig. 2007;37(12):925-32. doi: 10.1111 / j.1365-2362.2007.01888.x

14. Assmann-Stiftung für Prävention. PROCAM-Gesundheitstest [Internet]. 2018. [cited 2020 May 25]. Available from: https://www.assmannstiftung.de/procam-tests/

15. Genetics Home Reference. Inheriting Genetic Conditions [Internet]. Lister Hill National Center for Biomedical Communications U.S, National Library of Medicine, National Institutes of Health and Department of Health \& Human Services. 2020, 31 p. [cited 2020 May 20]. Available from: https://ghr.nlm.nih.gov/primer/inheritance/familyhistory

16. Matsudo S, Araújo T, Matsudo V, Andrade D, Andrade E, Oliveira LC, Braggion G. International physical activity questionnaire (IPAQ): study of validity and reliability in Brazil. 2001;6(2):6-18. doi: 10.12820/rbafs.v.6n2p5-18

17. Babor TF, Higgins-Biddle JC, Saunders JB, Monteiro MG. AUDIT - The Alcohol Use Disorders Identification Test Guidelines for Use in Primary Care Alcool. Second edition [Internet]. World Health Organization. Department of Mental Health and Substance Dependence. 2001 [cited 2018 Aug 20]. Available from: https://apps.who.int/iris/handle/10665/67205. 
Risk factors for coronary artery disease in nursing students Moraes HSC, Flores PVP, Cavalcanti ACD, Figueiredo LS, Tinoco JMVP.

18. Costa ALS, Polak C. Construction and validation of an instrument for the assessment of stress among nursing students. Rev Esc Enferm USP. 2009;43(Esp):1017-26. doi: 10.1590/S0080-62342009000500005

19. Fagerström KO, Schneider NG. Measuring nicotine dependence: a review of the Fagerström Tolerance Questionnaire. J Behav Med. 1989;12(2):159-82. doi: 10.1007/BF00846549

20. Ministério da Saúde (BR). Guia alimentar: como ter uma alimentação saudável [Internet]. Brasília: Ministério da Saúde, 2006. 31 p. [cited 2018 Aug 13]. Available from: http://bvsms.saude.gov.br/bvs/publicacoes/guia_alimentar_alimentacao_saudavel.pdf.

21. Medronho RA, Bloch KV, Luiz RR, Werneck GL. 2009. Epidemiologia. São Paulo. Editora Atheneu.

22. Rosa PBZ, Giusti L, Ramos M. Food and nutritional education to residents university student housing. Rev Ciênc Saúde. 2016;9(1):15-20. doi: $10.15448 / 1983-652 X .2016 .1 .20852$

23. Sanchez EC, Méndez MO, Ramírez TC, García AB, Domínguez LV, Palma NG, et al. Cardiovascular risk factors among nursing students of a public university. Enferm Univ. 2016;7(3):200-7. doi: 10.1016/j.reu.2016.09.004

24. Dias PS, Brito JAS, Costa AP. The influence of socio-economic condition on eating behavior among male academics. Rev Eletrôn Adm Turismo. 2017;(8)4:927-944. doi: 10.15210/REAT.V814.7368

25. Floody PD. Analysis of cardiovascular risk factors in young university students according to their nutritional status. Nutr Hosp. 2015;32(4):1820-1824. doi: 10.3305/nh.2015.32.4.9502

26. Fontela PC. Study of conicity index, body mass index and waist circumference as predictors of coronary artery disease. Rev Port Cardiol. 2017;36(5):357-64. doi: 10.1016/j.repc.2016.09.013

27. Vijayalakshmi P, Thimmaiah R, Reddy S, Nikhil SSN, Kathyayani BV. Gender Differences in Body Mass Index, Body Weight Perception, weight satisfaction, disordered eating and Weight control strategies among Indian Medical and Nursing Undergraduates. Invest Educ Enferm. 2017;35(3):276-84. doi: 10.17533/udea.iee.v35n3a04

28. Garrett SL, Pina-Thomas DM, Peterson KA, Benton MJ. Tracking physical activity in baccalaureate nursing students in the United States prior to graduation: a longitudinal study. Nurse Educ Today. 2019;80:28-33. doi: 10.1016/j.nedt.2019.05.038

29. Faria GS. Study of anxiety, depression and physical activity levels of university students. JCBS [Internet]. 2017 [cited 2018 Dec 20];3(1):18-23. Available from: http://publicacoes.facthus.edu.br/index.php/saude/article/view/160

30. Fernani DCGL, Cortez GM, Santos IA, Pacagnelli FL, Massetti TS, Silva TD, et al. Anthropometric profile, physical activity level, degree of anxiety, and posture in college students. Fisioter Pesqui. 2017;24(20):191-7. doi: 10.1590/1809-2950/17160324022017

31. Thwaite TL, Heidke P, Williams SL, Vandelanotte C, Rebar AL, Khalesi S. Barriers to healthy lifestyle behaviors in Australian nursing students: a qualitative study. Nurs Health Sci. 2020;1-8. doi: 10.1111/nhs.12749

32. Sá SCA, Silva RM, Kimura CA, Pinheiro GO, Guido LA, Filho IMM. Stress in university teachers of the health area of a private faculty of the federal district environment. Rev Cient Sena Aires. [Internet]. 2018 [cited 2018 Dec 20];7(3):200-7. Available from: http://revistafacesa. senaaires.com.br/index.php/revisa/article/view/321/231

33. Silva KKMD, Martino MMF, Bezerra CMB, Souza ÂML, Silva DMD, Nunes JT. Stress and quality of sleep in undergraduate nursing students. Rev Bras Enferm. 2020;73(Suppl1):e20180227). doi: 10.1590/0034-7167-2018-0227

34. Lopes HS, Meier DAP, Rodrigues R. Sleep quality among nursing students and associated factors. Semina Cienc Biol Saude. 2018;39(2):12936. doi: 10.5433/1679-0367.2018v39n2p129

35. Segundo LVG, Cavalcanti Neto BF, Paz DA, Holanda MMA. Features related to quality of sleep in medical students. Rev Bras Neurol Psiquiatr[Internet]. 2017 [cited 2020 May 22];21(3):213-23. Available from: https://rbnp.emnuvens.com.br/rbnp/article/view/208

36. Boostel R, Félix JVC, Major CB, Pedrolo E, Vayego AS, Mantovani MF. Stress of nursing students in clinical simulation: a randomized clinical trial. Rev Bras Enferm. 2018;71(30):967-74. doi: 10.1590/0034-7167-2017-0187

37. Maciel MED, Vargas D. Alcohol consumption among nursing students. Rev Pesqui: Cuid Fundam. 2017;9(1):64-70. doi: 10.9789/21755361.2017.v9i1.64-70

38. Rodríguez AA, Murillo AA, Rivera RJ, Montalván EE, Duarte KG, Urrutia AS, et al. Validity of the Methods of Prediction for Cardiovascular Risk in Latin America: Bibliographic Review. Rev Méd Hondur[Internet]. 2017 [cited 2018 Dec 20];85(1-2). Available from: http://www.bvs.hn/ $\mathrm{RMH} / \mathrm{pdf} / 2017 / \mathrm{pdf} /$ Vol85-1-2-2017-15.pdf 